\title{
MATHEMATICS AND THE FUTURE OF SCIENCE
}

\author{
MARSHALL H. STONE
}

It is indeed a great honor to be asked to deliver the Gibbs Lecture this year, and one which I have accepted in a humble spirit. The work of Josiah Willard Gibbs comprised a series of achievements in applied mathematics of such beauty and perfection that the most fitting tribute which could be offered to him here would be a scientific paper written in a spirit of emulation. Such a tribute lies beyond my powers. My interests as a mathematician have been directed toward pure mathematics; and I have never entertained the ambition of contributing explicitly to the advancement of applied mathematics or cherished the illusion that I might have such a contribution to make. I have not, however, been one of those mathematicians whose joy in their mathematical achievements is intensified by the belief that these are to remain forever useless and unused outside the happy realm of pure mathematics. On the contrary, the satisfaction which I have derived from working in mathematics has been increased by the knowledge that what I have done could be seen, with few exceptions, to have some bearing upon mathematical physics or upon some other branch of applied mathematics. I have taken much pleasure in acquainting myself with the ways in which the results of pure mathematics could be turned to good account in probing Nature's secrets and rendering them intelligible-and, eventually, useful. My tribute to Gibbs will therefore take the form of an expression of faith in the growing importance of mathematical thought for the future of science. I wish on this occasion to speak of my reasons for believing that the wonderful development of mathematics which we have witnessed in our time holds the seeds of brilliant scientific progress in time to come.

In a sense, all that can be said upon this theme is summed up in a syllogism: science is reasoning; reasoning is mathematics; and, therefore, science is mathematics. Because this simple argument seems to me to express so well the essence of the inescapable connections between science and mathematics, I wish to devote a few words to clarifying and justifying the premisses upon which it rests. The minor premiss raises a point which has been at issue between logicians and

The thirtieth Josiah Willard Gibbs Lecture, delivered at Rochester, New York on December 27, 1956, under the auspices of the American Mathematical Society; received by the editors December 27, 1956. 
mathematicians since the publication of Principia Mathematica. I think both parties are right-the logicians when they claim that mathematics can be formalized in certain systems of formal logic, the mathematicians when they rejoin that the systems of formal logic are themselves special mathematical systems which should be treated by the methods of mathematics. While I have tried in my own mathematical work, some of which is to be read by title at this meeting, to provide evidence for the mathematicians' side in this debate, I believe that the issue should be resolved by equating formal logic with mathematics, as has been done here. It is of some importance for our later considerations that this equation recognizes mathematics as embracing much more than the study of quantity and number. Indeed, it requires us to conceive of mathematics as the study of general systems comprising designated objects and designated relations among them; and to regard the quantitative or numerical aspects of particular mathematical systems as accidental, rather than as essential or characteristic, phenomena for mathematics as a whole. It would, for instance, be wrong from this point of view to reject a scientific theory as nonmathematical merely because the theory is nonquantitative.

Our major premiss clearly hinges upon a question of definition: what are we to mean by the term "science"? The answer which we propose to give here is precisely the one which validates this major premiss-namely, that science comprises those and only those disciplines in which reasoning plays a predominant and essential part. While this is hardly the sense in which the term "science" is used in popular American speech or writing, weightier objections can be raised against our definition and are entitled to a thoughtful review. Should not the definition of "science" be so framed as to refer explicitly to the roles of observation, experiment, and prediction? Is it not necessary to take into account the distinction between inductive and deductive reasoning? Does not the subject matter of a discipline have some bearing upon its classification in the present context? Is not our definition too inclusive in some respects, too exclusive in others? Such queries as these plainly deserve some kind of comment, even though the circumstances compel me to be succinct in making it. Any intellectual discipline whatever deals with recorded observations, seeking to find in them some sort of order or pattern and to view them in the light of reason. It is surely not until observation becomes something more than the casual or the systematic collection of facts that it can be thought of as a characteristic feature of science. Otherwise we would have to regard history and literary or aesthetic 
criticism as sciences, for example, and would soon realize that we had appealed to a criterion without value. On the other hand, if we were to require that the term "science" be applied to no disciplines except those in which systematic, directed, and controlled observations-in a word, experiments - are an essential element, we could then not include geology or meteorology among the sciences. We might try to avoid these unsatisfactory extremes by choosing a definition in terms of directed observations. It seems to me however that this attempt must fail because of the difficulty in deciding what shall be meant by the phrase "directed observation." How can we differentiate the kinds of observation made by the historian, the systematic botanist, and the meteorologist by the criterion of "directedness"? I would say that we can do so only by determining to what extent observations in these different disciplines are guided by and related to the reasoned theoretical structures which they have built up over the years. But if this is so we have returned to a characterization of science based upon the prominence of the rational element. On another occasion [1] I suggested that concern with prediction distinguishes the scientific from the nonscientific disciplines. Without altering the position which I took then, I must now observe that this criterion too leads us back once more to the definition with which we started here. Indeed, the possibility of making predictions, either deterministic or statistical, rests squarely on the ability to reason closely from such general principles as may have emerged from previous observation and study. The more we seek to refine our predictions, the more we must refine both these principles and the arguments by which we discover their implications. From our point of view, to say that history is not a science because it does not predict is merely one way of calling attention to the fact that in the study of history reasoning plays neither a predominant nor an essential role.

Although this discussion of the meaning which is to be attached to the term "science" is far from complete, enough has perhaps been said to qualify as a usable analytical tool the definition we have proposed here and to elucidate our conclusion that science is mathematics. Nonetheless, a strictly logical analysis of the connections between science, reasoning, and mathematics leaves much to be desired because its scope is too narrow to include any account of the growth and development of those disciplines which we accept as sciences. Looking backward, we see that the sciences we call astronomy, physics, and chemistry have passed through various stages, beginning as practical arts in very remote times, becoming in due course subjects of scholarly study and speculation, and emerging at last as 
intellectual disciplines centered about elaborate mathematical theories. Indeed, in each of these three cases we have little difficulty in identifying the moment at which the transformation into the scientific phase began. These moments are marked, respectively, by the contributions of Eudoxus, of Galilei and Newton, and of Lavoisier and Priestley. While these examples may serve to strengthen our conviction that it is the rational component of an intellectual discipline which identifies it as a science, they also force us to recognize that in every branch of knowledge this component has to develop, often very slowly, from a few small seeds. As we look around us today we see such seeds vigorously sprouting in many fields, and on the point of germinating in as many others. These fields of knowledge are not only those which deal with the physical and biological worlds, but also those which are concerned with the mind of man and with his behavior as a social being. We are without any doubt witnesses to the birth of new sciences, and we can be sure that in many of them we shall see rapid development along theoretical, mathematical lines. Indeed, we have the strongest logical and historical grounds for believing that the tendency towards the mathematicization of knowledge, which began with the Greeks, will be broadened and accelerated in the coming century. That this tendency will require and stimulate advances in mathematics itself is inevitable. To some extent it will even be directed and conditioned by the progress which can be made by mathematicians, as we can infer from a consideration of the history of modern physics. The future of science is in this sense tightly bound together with the future of mathematics. The extraordinarily luxuriant growth of pure mathematics in our time encourages us to look with optimism and enthusiasm to a future in which science will draw bountiful nourishment from the fruits of our husbandry in the mathematical field.

In spite of logic and the lessons of history it would be very foolish to expect that mathematics will be able to make its fullest contribution to the advancement of science unless mathematicians themselves take an active and well-informed interest in its applications to the multiplying fields of science, old and new. Even though the proliferation of mathematical modes of thought into the most diverse domains of learning may rightly be regarded as inevitable, it can easily be retarded or deflected by obstacles which will have to be identified and removed if the development of the sciences is to be accelerated. While it may be true that the world will beat a path to the door of the man who builds a better mouse-trap, as Emerson once said, we mathematicians must recognize that, however good the mouse-traps we invent, 
the world may be very slow to realize its need of them and equally slow to discover the most convenient and satisfactory paths to our door. The task of attracting the world's attention to our stock of mouse-traps and marking out some of the approaches to it is primarily the task of mathematicians. It is a difficult, challenging task which cannot be satisfactorily handled until we ourselves have gained a clearer and more profound understanding of the changes wrought by mathematical, scientific, and technological progress in the nature of applied mathematics and its relation to pure mathematics on the one hand and to science and technology on the other. Of all the different aspects of our central theme which might be discussed in greater detail, there is none which seems to me so timely or of such obvious importance as the evolution now taking place in applied mathematics. I propose therefore to speak during the remainder of my allotted time about the subject of applied mathematics.

This subject is one which has evoked a great deal of discussion and writing in recent years. It is therefore impossible to avoid going over a good deal of familiar ground in what I am about to say here. Where I can do so, I shall, of course, touch only lightly on matters which have been thoroughly handled in other places. For more extensive details relating to such matters reference may be made to one of the most elaborate of the recent treatments of our subject, the report of the National Research Council's Committee on Training and Research in Applied Mathematics [2], on which I had the privilege of serving. I shall try to emphasize instead those considerations and points of view which seem to me to possess some degree of freshness, if not novelty. It is, indeed, my feeling that for a pure mathematician to offer a frank discussion of the current problems of applied mathematics is in itself something of a novelty.

Since the time when I first attempted to clarify my own point of view about the pursuit of applied mathematics, in an unpublished address delivered at the celebration of the University of Chicago's fiftieth anniversary, I have become increasingly aware of the tensions created by the existence of two different and philosophically opposed attitudes toward the applications of mathematics. In most discussions of the subject these tensions can be sensed even when no direct allusion is made to them. I have learned too that the attempt to discuss applied mathematics without frank statements of position from the participants is to invite confusion and ill-feeling. I therefore wish to preface my own remarks upon this subject with a clear indication of my own attitude. It took me rather a long time to understand the nature and the true significance of the two different attitudes which 
I have mentioned, though there was never any doubt in my mind as to my choice between them. It would have taken me even longer to arrive at a satisfactory statement of these matters, if I had not had the good fortune to come upon an essay of Whitney Griswold, President of Yale University, in which he probes the nature of the fundamental controversy in contemporary American educational circles [3]. He describes the conflict as one between liberal education and utilitarian education, and traces its origins to ancient times. The opposition is between that point of view which regards as good whatever develops the intellectual and spiritual powers of the individual and the point of view which regards as good whatever works or accomplishes useful results. Griswold quotes a wonderful passage from Francis Bacon, who says, "First, therefore, amongst so many great foundations of colleges in Europe I find it strange that they are dedicated to professions, and none left free to arts and sciences at large. For if men judge that learning should be referred to action, they judge well, but in this they fall into the error described in the ancient fable, in which the other parts of the body did suppose the stomach had been idle, because it neither performed the office of motion as the limbs do, nor of sense, as the head doth, but yet notwithstanding it is the stomach that digesteth and distributeth to all the rest. So if any man think philosophy and universality to be idle studies, he doth not consider that all professions are from thence served and supplied. And this I take to be a great cause that hath hindered the progression of learning, because these fundamental knowledges have been studied but in passage. For if you will have a tree bear more fruit than it used to do, it is not anything you can do to the boughs, but it is the stirring of the earth and the putting new mould about the roots that must work it." Is this not admirably put indeed? I find it so, and am quite content to take my stand with Francis Bacon. I hold, as he does, that utility alone is not a proper measure of value, and would even go so far as to say that it is, when strictly and short-sightedly applied, a dangerously false measure of value. For mathematics, which is at once the pure and untrammelled creation of the mind and the indispensable tool of science and modern technology, the adoption of a strictly utilitarian standard could lead only to disaster: it would first bring about the drying up of the sources of new mathematical knowledge and would thereby eventually cause the suspension of significant new activity in applied mathematics as well. In mathematics we need rather to aim at a proper balance between pure theory and practical applications, as Bacon's words counsel us to do. The peculiar importance which maintaining such a balance may have for 
our times was emphasized not very long ago by Alan Waterman, Director of the National Science Foundation, in an address delivered before this Society and the Mathematical Association [4]. As he pointed out, "... mathematics, in a sense, bridges the gap, real or imaginary, which exists between the sciences and the humanities. The exigencies of modern technology have attracted many of the sciences away from their original orbits in the realm of natural philosophy. Mathematics, too, has had its practical part to play in the modern world, but in the process it has never lost its scholarly aura. It occupies an honored place perhaps equally among the humanities as among the physical sciences." It is my fondest and most cherished hope that mathematics, despite the strains to which it is subjected by the expansion of its own boundaries and the demands of the modern world, may forever preserve its essential unity and may thus continue to aspire to this position of twofold honor, always setting for itself those high standards of intellectual achievement which alone can qualify it as worthy to occupy such a place.

Let me now turn to a consideration of those developments in mathematics which compel us to revise and to reappraise our estimates of the relations between pure and applied mathematics. For this purpose it is necessary to examine some of the historical factors which have combined to produce the present situation. Approximately at the turn of the century mathematics entered upon a new phase of its development, destined to bring about a profound transformation of its substance and structure. The changes which have been wrought over the short period of less than sixty years are little short of amazing, in variety as well as in magnitude. Their extent can be quite accurately gauged by comparing the curricula of 1900 or 1920 with those of today; or by noting the long list of new mathematical concepts, methods, and disciplines, hardly known fifty years ago, which form an essential part of the intellectual equipment of any modern mathematician who pretends to a general knowledge of his subject. This flowering of pure mathematics in the twentieth century has involved the specialization inseparable from an intensive exploration of new possibilities, the continual testing of new ideas for their viability, and a ceaseless struggle to comprehend in universal terms the rapidly accumulating products of fruitful research. It was an essential condition of this flowering that mathematicians should first have recognized and acted upon the fact that mathematics is not closely bound to the material world or to physical reality-if, indeed, it is bound at all. As a necessary consequence of this recognition, the pure mathematicians of our century have sought the future of mathematics not 
in technical virtuosity alone but also in abstraction and universality. Throughout its long historical evolution, Western mathematics had dealt, consciously or unconsciously, with mathematical aspects of the real world - the properties of numbers, the geometry of the space in which we move, the dynamics of the moving things about us. Mathematicians thought of the theories which they constructed about these aspects of reality as calculated to yield a philosophical understanding of nature as well as some practical mastery of it. All this appears clearly in the achievements of such great mathematicians as Archimedes, the Bernoullis, Euler, Laplace, Gauss, and Cauchy, whose contributions are honored today by both the applied mathematician and the pure. It appears equally in the uneasiness occasioned by the discovery of noneuclidean geometry early in the nineteenth century, when it began to be plain to everyone that mathematics would henceforth have to deal with two geometries, only one of which could govern the space of our experience-and, worse, that skillful measurements such as those carried out by Gauss might be insufficient to decide which of the two applies to the physical world. The full implications of this profound new insight into the freedom of mathematical theory from physical necessity made themselves felt but slowly, partly because the nineteenth century still had an immense task to perform merely to build upon the foundations which had already been laid, partly because the techniques developed in an earlier time were in urgent need of overhauling and refinement before they could be deemed satisfactory for the work which was to be done. Thus it fell in large measure to the twentieth century to make the most of an insight which was gained in the early part of the preceding one. The instrument fashioned for the accomplishment of this task was the axiomatic or postulational method, now so well known that I do not need to describe it here. There are those who profess to see in the use of the postulational method the essence of modern pure mathematics. To my mind it is a mistake to suppose or to suggest that a mere instrument, however powerful or characteristic, can contain in itself the essence of such an intellectual movement as that which has swept the mathematicians of this generation forward to achievements certain to stamp an indelible mark upon the mathematics of the future. Rather it is what this instrument has made possible - the dissection of mathematical concepts into their elemental components, the recombination of these components into new constructs of intrinsic interest, the critical evaluation of alternative approaches to the important mathematical theories, the unification of hitherto unconnected branches of mathematics-that best expresses the spirit of 
modern pure mathematics. Though concentration of one's attention on the details might at first seem to indicate the contrary, pure mathematics does in fact continue to revolve about the great central problems of number theory, of geometry, and of analysis, which deal with matters fully as concrete as the abstractions of the atomic or nuclear physicist. Pure mathematics, despite an altogether natural preoccupation with the very fruitful independent development which has been in progress in our times, has never ceased, in the words of Francis Bacon, to "refer learning to action." In truth, it has continued to draw inspiration from the oracle of nature, and has remained constantly aware of the role it plays in increasing the applied mathematician's resources for understanding the world in which we live. Interesting testimony to this effect is offered in the National Research Council report mentioned above [2] when it notes that "insofar as lines of communication with modern physics are being maintained at all by mathematical activities in this country, some pure mathematics faculties have managed to tend them better than any of the applied mathematics centers ...." But, to repeat what I have insisted upon above, pure mathematicians cannot accept "reference to action" as the sole criterion by which their work is to be judged.

While pure mathematics was growing in this rapid and remarkable fashion for more than five decades, applied mathematics too has experienced highly significant changes-on the one hand a radical reorientation, and on the other an extensive enlargement of its scope. The most spectacular developments, generally agreed to have been of a genuinely revolutionary character, were those involving the foundations of physics. The abandonment of the classical views of dynamics which stemmed from Galilei and Newton in favor of relativity theory and quantum theory opened up to mathematical analysis great masses of data which had proved refractory to treatment by the classical methods of mathematical physics. It was virtually inevitable that theoretical physics should have shifted the center of its chief interest into the exciting new fields which begged for exploitation, leaving to a sort of marginal cultivation many traditional domains of the science - in particular, hydrodynamics, the theory of elasticity, and other aspects of the mechanics of continua. These fields were henceforth of greater concern to engineers and a few mathematicians than they were to physicists. At the same time chemistry, which in the nature of things had hitherto been but lightly touched by mathematics - and this mainly through the intervention of thermodynamics and statistical mechanics-now felt the heavy impact of the new atomic theories. Despite the grave imperfections which 
have since been revealed through the accumulation of new data about the elementary particles and the nucleus, these theoretical developments undoubtedly constitute the crowning achievement of applied mathematics. This achievement would have been impossible without the use of mathematical tools, such as the tensor calculus and the theory of continuous or topological groups, which the physicist of 1900 would presumably have regarded as mere mathematical curiosities. For the most part these tools were already available in the stocks prepared by the mathematicians of an earlier day. One of the reasons why pure mathematics has tended to maintain a certain amount of contact with modern theoretical physics, as noted above, is that the new uses to which these tools were put posed novel, intrinsically interesting, and relatively difficult questions about traditionally important branches of mathematics. Much effective mathematical research has been devoted in recent years to just such questions, particularly to those concerning the representations of topological groups and the theory of operators in Hilbert space. On the other hand, theoretical physics, already highly mathematical in form, has been drawn into abstractions and speculations of a more or less metaphysical character for the exploration of which the axiomatic or postulational method peculiar to modern pure mathematics has proved itself to be a most powerful instrument. Many illustrations could be cited, but the two most striking are perhaps the papers of Dirac [5] and Yukawa [6] in which the positron and the meson were postulated and subjected to mathematical investigation before either elementary particle was known to have physical existence. At the present time the mathematical and conceptual difficulties of field theory have apparently produced a new crisis in theoretical physics which seems to call for new physical insights and new mathematical tools. From a mathematician's point of view it is not unlikely that part of the physicist's present troubles arises from his inadequate mastery of modern mathematical methods and concepts. It is true that most of what has been accomplished in modern theoretical physics has been based on nineteenth century mathematics, and it is conceivable that this is not going to be sufficient for further progress.

If the mathematical successes in the field of physics have been the most spectacular and impressive, the twentieth century has witnessed many other advances in applied mathematics. As in the case of quantum theory, many of these advances depend in one way or another upon the use of mathematical statistics. We have learned that many of the most fundamental processes of nature seem to defy any exact deterministic characterization and must be thought of in 
statistical terms. This is true not only of the behavior of the elementary particles of physics, but also of the mechanisms governing heredity. The modern theory of genetics, which is perhaps the most highly developed and mathematical part of theoretical biology, is thus founded on statistical principles. Because of the tremendous scope of its applications, ranging all the way from theoretical physics to the social sciences, mathematical statistics has undergone a rapid and extensive development so that it now enjoys the status of an independent discipline. Mathematically we now know that it is a branch of measure theory, which is linked with the real world through a few simple principles embodying the essence of inductive reasoning. There is, of course, some disagreement as to how these principles should be formulated. It has always seemed to me that they all have to be based on a single rule of thumb, "A sufficiently improbable event may be ignored." In making decisions according to this rule, the role of mathematics is to provide the measure-theoretic calculations of interrelated probabilities and the role of practical insight is to determine for each concrete situation which probabilities are sufficiently small. Why the real world should be amenable to such a rule is, I think, a philosophical question no more - and no lessmysterious than the problem of why it should be amenable to logic. The fact that these questions are but two aspects of the ultimate problem of the connections between mind and matter leads me to think that distinguishing between inductive and deductive reasoning can be of little help in defining what we mean by "science." In any case, so far as techniques are concerned, the development of mathematical statistics in its modern form has shown that virtually all the detailed procedures of inductive reasoning are deductive in character.

It would be illuminating, if I had the knowledge and the time for it, to depict in detail the way in which applied mathematics has ramified in the course of the present century. Apart from what has taken place in the physical sciences other than physics and chemistry, we should have to examine at some length the attempts to fashion mathematical theories of certain biological phenomena. Closely related to the work in genetics, to which we have already alluded, are the mathematical studies of the growth of populations and of competing species, with their obvious practical significance. We should mention also the mathematical treatment of various physiological problems, including the theory of nerve-networks and the brain. Then we should go on to survey the emergence of new mathematical theories of various psychological and social phenomena, such as the deduction from 
communication theory of the observed statistical regularities in language, the interpretation of certain competitive situations in terms of game theory, or the application of linear programming to managerial problems. The list of such theories would already be a long one. It seems to me that a rather special interest attaches to the novel and promising applications of mathematics currently being made in fields which were once deemed inaccessible to mathematical treatment, either on grounds of principle or because they had already shown themselves recalcitrant to it. More often than not it is the possibility of using novel mathematical tools-as, for example, the refinements of mathematical statistics or the theory of games-which has permitted some progress to be made in these new directions. I believe that we are entitled to expect a great deal of further progress in the immediate future, but that we must be prepared to see it coupled with the development of new mathematical methods as well as with direct applications of those already available. Nevertheless, optimism in regard to potential advances of this nature should be tempered with a considerable dose of caution. Even though there seems to be very good reason for optimism, it must be admitted that the role of mathematics outside the exact sciences is far from being solidly established by its achievements, save possibly in the field of genetics. There is in fact a large body of opinion, particularly in the social studies, which considers that the really important phases of the behavior of living beings will never yield to mathematical treatment-and in some cases not even to scientific treatment in the broadest sense of the term. Some of the most fascinating and significant intellectual adventures of the decades just ahead of us are likely to be experienced in attempts to determine the extent to which mathematical penetration of such unexplored domains is possible.

The technological demands of our age have begun to exert an increasingly strong pressure upon the development of applied mathematics, as it becomes necessary to answer more and more precisely a greater and greater variety of difficult questions arising in connection with the design, construction, or operation of novel, complex, or versatile machines. World War II presented some of these demands with a peculiarly high degree of emphasis and urgency, which have in the meantime been underlined, if anything, by the ensuing cold war. It seems plain that in the long run these demands will be just as insistently forced upon our attention by the competition between man and nature as by that between man and his fellow-man. The technological demands of the time have, in particular, played a major role in the revival of a branch of applied mathematics-the dynamics 
of continuous media-which for some time had suffered neglect at the hands of both mathematician and physicist, as we have already observed earlier in our discussion. The fact that new mathematical and physical insights seem to be imperatively needed in this field suggests that one reason for past neglect may have been the conviction that for the moment science was not yet ready to cope with the recognized obstacles to further progress. Certainly such a feeling could only have enhanced the attractions exerted by other domainsattractions which were in themselves strong enough to draw most mathematicians and physicists away from this classical domain of common interest. The technological applications of mathematics characteristically require numerical answers in quantity and thus place a premium upon computational routines and the mathematical skills involved in setting them up. The mechanization of these routines, itself dependent upon a high degree of technological proficiency, has been successfully undertaken in response to this obvious need and has important implications for the future. Not only is the utilitarian scope of applied mathematics very substantially enlarged because necessary computations can now be performed at such high speeds and at such relatively low cost in terms of effort, but in addition the mathematical art of computation has been lifted up to a higher and much more interesting level. It is not easy to foretell what varied influences the introduction of modern high-speed computing machines will have upon mathematics or upon the mutual relations of mathematics and industry. There is a distinct possibility that industry, guided by a thoroughly utilitarian outlook, will tend on the whole to confine its interest. in applied mathematics to the organization of working teams composed of applied mathematicians and computing experts charged with the task of turning out, with the highest possible degree of proficiency, specific answers to a limited range of specific questions. A heavy demand along these lines appears to be building up today in the United States. If this tendency should not be counterbalanced by the parallel development of a deeper interest in fundamental mathematics such as some of the leading industries here and abroad have consistently shown in the past, then there would be reason for viewing the future with certain misgivings.

The response of American mathematics to the broad trends and developments which we have been seeking to describe seems to me to have been significantly affected by certain circumstances peculiar to the American scene. These circumstances are to be explained in part, I think, by interpreting them as the product of America's experience as a nation of pioneers cut off by distance from the historic centers of 
their culture. Perhaps another factor, as suggested by President Griswold in the article cited above, has been the recent immigration of large numbers of men and women drawn from those elements of European society having the most tenuous contacts with the main intellectual centers of the continent. In America the creation of centers of research and advanced training in higher mathematics lagged far behind the developments of the eighteenth and nineteenth centuries in Europe. Despite the pioneer influence of such essentially isolated figures as Sylvester and Benjamin Peirce, no sustained interest in higher mathematics marked the growth of the American university until the closing decade of the last century. Thus the entire development of the great mathematical centers which now dot the country has taken place in little more than sixty years. A very significant feature of this development, apart from the fact that it coincided almost exactly with the great flowering of pure mathematics which we have described above, was the almost complete freedom accruing to the mathematicians of America from the cultural lag just mentioned. They were not bound by strong academic traditions nor hampered by powerful vested interests in their task of setting the course which higher mathematics should follow in America. At the same time the highly pragmatic outlook of the American industrialist and business man-a product also of the pioneer experience-prevented American mathematics from being called on to play anything but the most modest utilitarian role during this critical period. In consequence, the mathematicians of this country were free to direct their efforts towards the great central themes of modern mathematics and thus came to participate both as teachers and investigators in the exciting progress of pure mathematics in the twentieth century. Indeed, American mathematics has been conspicuously marked by tendencies towards abstraction and generality which must seem very surprising to anyone convinced of the utilitarian orientation of American culture. If American mathematics has enjoyed a singular independence from utilitarian demands and has thus been enabled to achieve important intellectual progress, it has also been placed in a false position both intellectually and professionally. The utilitarian philosophy is by no means confined to the United States, though it is perhaps as strong here as anywhere in the world. It has had an influence not only upon the industrial applications of science, including mathematics, but also upon the relations between the various branches of science, and perhaps nowhere a stronger influence than in the United States. Insofar as mathematics is concerned the effects of the utilitarian attitude are particularly significant because all the 
sciences, as we have tried to show here, exhibit a common trend towards an increased dependence upon mathematical reasoning and thus need an increasingly deep and intelligent appreciation of the nature and resources of modern mathematics. It need hardly be pointed out that in this era of specialization much of the best work in applied mathematics is done by men who regard themselves not as mathematicians at all but as physicists, chemists, or biologists. And this, it might be added, is bound to be the case under any circumstances because good work in applied mathematics must be concerned at least as much with nature as with mathematics. The majority of scientists, at least in this country, fall easily into a strictly pragmatic and utilitarian point of view towards mathematics, which they finally come to consider merely as a more or less useful tool concerning which it is unnecessary to know much more than the immediately useful features. Quite literally the scientist who slips into this attitude accepts what works as true, so far as mathematics is concerned. In this way communication has broken down to a very grave extent between pure mathematics and many branches of applied mathematics. If mathematics is to be restored to its true position and thus enabled to play its part intellectually and professionally in the development of science and its industrial applications, then these lines of communication must be reëstablished within the learned world and extended also into all parts of the world of technology.

While the means for redressing the balance between the pure and the applied aspects of mathematics and for restoring these lines of communication lie outside the purview of this address so far as any detailed discussion is concerned, I shall direct my closing remarks to stressing once more that we mathematicians have the primary reresponsibility for identifying and using them. This is all the more true because the most important means of influencing the relations between mathematics and man's intellectual and industrial activities is mathematical education. Financial means can properly be of concern to us; but if in the future industry were to contribute to the promotion of mathematics as generously as private individuals and the government are now doing, our worries on that score would speedily be put to rest. What we must realize above all is that the mathematical education of the past has to a disturbing extent failed to lay the groundwork for the kind of intercommunication among mathematics, the various sciences, and engineering, which we now see to be necessary. By and large mathematical instruction has been little touched, except at the graduate level, by the mathematical advances of this century. Until it is, such improvements as are made in it will 
be mainly of a technical or pedagogical nature. The most serious obstacle to a modernization of the mathematical curriculum is the utilitarian spirit which pervades secondary education and governs the manner in which scientists teach the use of mathematics in the various fields where it is applied. Because students have been taught in high school to understand mathematics more in its practical aspects than in its technical and logical fullness, they arrive in college with their mathematical abilities blunted instead of sharpened and strengthened as they should have been. They are further encouraged to take a utilitarian view of mathematics by the way they see it handled-and, at times, mishandled-in nearly every scientific or engineering course they may elect. The consequence is that the attempt to teach calculus properly or to introduce the elements of modern algebra into the curriculum is of ten resented by students and criticised by other departments. Despite this difficulty some progress has been made. Much more, however, is essential before American mathematics can be considered to be in a sound and healthy state. For the words of Francis Bacon quoted above surely have their application to this matter- "if you will have a tree bear more fruit than it used to do, it is not anything you can do to the boughs, but it is the stirring of the earth and the putting of new mould about the roots that must work it."

\section{REFERENCES}

1. Marshall H. Stone, Science and statecraft, Science vol. 105 (1947) pp. 507-510.

2. F. J. Weyl, $A$ survey of training and research in applied mathematics in the United States, a Report by the National Research Council Committee on Training and Research in Applied Mathematics, 1955, reproduced as a monograph by the Society for Industrial and Applied Mathematics.

3. A. Whitney Griswold, What we don't know will hurt us: the power of liberal education, Harper's Magazine, July, 1954, p. $76 \mathrm{ff}$.

4. Alan T. Waterman, The National Science Foundation program in mathematics, Bull. Amer. Math. Soc. vol. 60 (1954) pp. 207-214.

5. P. A. M. Dirac, Proc. Roy. Soc. London. Ser. A, vol. 126 (1929-30) pp. 360365; vol. 133 (1931) pp. 60-71.

6. H. Yukawa, Proceedings of the Physico-Mathematical Society of Japan vol. 17 (1935) pp. 48-57.

The University of Chicago 